\title{
PATOČKA Y ARENDT SOBRE EL MOVIMIENTO INICIAL DE LA EXISTENCIA HUMANA
}

\author{
Agustín Serrano de Haro ${ }^{1}$ \\ Instituto de Filosofía, CSIC, Madrid, España
}

\begin{abstract}
Resumen: El conocido paralelismo entre las formas de la acción que Hannah Arendt distingue y el triple movimiento de la existencia humana que Jan Patočka presenta debe dar paso a un examen detenido que valore las diferencias muy significativas entre ambos modelos. Este artículo toma en consideración la distancia descriptiva que separa la tematización del orden básico de la existencia, bien como labor incesante del cuerpo menesteroso, bien como acogida de la necesidad corporal por los otros. Frente a la naturalización arendtiana de la labor como metabolismo con el medio, el enfoque genético del pensador checo asume la precedencia de la intersubjetividad en la experiencia infantil del mundo. Se apunta también cómo esta divergencia de base condiciona la comprensión de los otros órdenes de la acción.
\end{abstract}

Descriptores: Labor $\cdot$ Acogida $\cdot$ Arendt $\cdot$ Patočka $\cdot$ Naturalización

Abstract: The well-known parallelism between the forms of action that Hannah Arendt distinguishes and the triple movement of the human existence that Jan Patočka presents has to give rise to a precise study that puts emphasis in the very meaningful differences between both models. This paper underlines the descriptive difference that separates the thematization of the basic order of the existence, as incessant labor of the needy body or as welcome of the bodily necessity by the others. Facing the arendtian naturalization of the labor as metabolism with the environment, the genetic focus of the Czech thinker assumes the precedence of the intersubjectivity in the childish experience of the world. We also point out how this basic divergence conditionates the understanding of the other orders of the action.

Keywords: Labor $\cdot$ Welcome $\cdot$ Arendt $\cdot$ Patočka $\cdot$ Naturalization.

A. El esquema arendtiano que divide la acción humana en la labor de nuestro cuerpo, el trabajo de nuestras manos constructoras y la praxis intersubjetiva que cuida de la polis, resulta hoy tan conocido que corre más bien el riesgo de tornarse un tópico inerte. Son tres, y en principio solo tres, los órdenes que estructuran la vida activa. Y ellos no precisan siquiera de instancias mediadoras o de nexos vinculantes que salven o medien la profunda heterogeneidad que los separa; cada uno se mueve en un horizonte distinto de espacio y tiempo, cada uno supone capacidades diversas de la condición humana activa, cada uno engendra ideales incompatibles de acción

\footnotetext{
${ }^{1}$ Departamento de Filosofía Teorética y Filosofía Práctica. E-mail: agustin.serrano@cchs.csic.es. Este trabajo ha surgido en el marco de actividades del proyecto de investigación Fenomenología del cuerpo y análisis del dolor II. FFI2017-82272-P. Programa Estatal de Fomento de la Investigación Científica y Técnica de Excelencia, Ministerio de Economía, Industria y Competitividad, Gobierno de España.
} 
y oculta quizá patologías propias. No solo el sujeto individual sino también la pluralidad intersubjetiva de los seres humanos se articula y despliega en forma distinta en la comunidad natural de labor y consumo, en la sociedad de artesanos y constructores y en la comunidad política de agentes comprometidos con la polis. Al cabo, la labor se identifica con la nuda vida del animal menesteroso, necesitado a perpetuidad de los bienes de consumo de que depende su supervivencia; el trabajo, en cambio, constituye el mundo estable de las cosas de uso y depara una trama duradera de objetos con sentido; y solo la praxis hace posible el espacio de la acción política y el tiempo de la historia. Cada uno de estos vectores de la vida activa trae así a manifestación un ámbito heterogéneo de la realidad: la naturaleza abrumadora, infinita, anónima; el mundo estable de útiles y objetos, por entre los que discurre la existencia de los mortales; el mundo intersubjetivo de sujetos irrepetibles que asumen su condición de tales en la coexistencia imprevisible.

Esta tripartición arendtiana de las modalidades de acción no es un elenco nominalista, que cuente o recuente lo que el ser humano hace, que observe aires de familia entre las innumerables actividades y les asigne luego etiquetas manejables. Tampoco es una construcción teórica que se sitúe por encima de los fenómenos de la acción y que pudiera acaso remitir esta diversidad tan marcada a una única facultad de obrar, a una voluntad libre como principio de una antropología filosófica. El enfoque descriptivo no es, pues, empirista, como en un recorrido por las conductas de los seres humanos, ni es tampoco racionalista, como en una teoría metafísica del lugar del hombre en el cosmos. Lo que el ser humano hace es también, en medida esencial, lo que le hace; la acción da forma y constituye su ser, y le permite así seguir haciendo mundo y haciéndose en el mundo. En las páginas que siguen no pretendo devanar algunas de las madejas ontológicas de esta fecunda comprensión de la acción. Me interesa considerar, más sencillamente, cómo los análisis fundamentales de Jan Patočka acerca del triple movimiento de la existencia humana se atienen con fidelidad al modelo fenomenológico arendtiano al mismo tiempo que divergen de él de una forma que es significativa, original, creadora. En el enfoque del filósofo checo, la acción humana se identifica todavía más claramente con, por así decirlo, el ejercicio de la existencia, "el oficio de vivir", que discurriría, en efecto, en tres dimensiones heterogéneas pero dependientes; tres direcciones diversas pero superpuestas unas a otras. Patočka evita las denominaciones arendtiantas y habla más bien del enraizamiento o anclaje en los otros, de la afirmación poderosa del sujeto $\mathrm{y}$, en tercer lugar, de la entrega o sacrificio. Me interesa esbozar aquí un pequeño contraste descriptivo, no ya de cada una de estas dimensiones patočkianas con su correspondiente arendtiano, sino solo de la dimensión primera, de la modalidad original y básica de la acción: labor en Arendt, arraigo o anclaje en Patočka. Mi idea es que una suerte de concordancia discorde, o de discordancia concorde, rige 
entre el gran filósofo de la disidencia checa y la gran filósofa del republicanismo cívico. Y que esta comunidad de espíritu con divergencia de análisis se observa con una especial claridad en la tematización del primer movimiento de la acción. En el estrato básico, los matices de la divergencia son además particularmente significativos, señaladamente relevantes.

En un cierto sentido, mi aportación resulta escasamente original. Fue el propio Patočka quien conectó expresamente sus planteamientos con los de $L a$ condición humana. Pero este reconocimiento explícito se encuentra en los Ensayos heréticos sobre filosofía de la historia, en el magnífico capítulo inicial del libro, y se produce al hilo de la meditación sobre qué sea un mundo humano pre-histórico; ${ }^{2}$ es decir, un hábitat humano en el que se labora y se construye, se vive, se convive y se muere sin haber todavía experimentado ni la acción política compartida ni la interrogación filosófica, y que por ello no ha conocido aún, de acuerdo con el pensador checo, la génesis de la propia Historia. Yo prefiero atenerme, en cambio, al largo ensayo "El mundo natural y la fenomenología", que, a mi juicio, ofrece la mejor tematización patočkiana de los tres movimientos de la existencia humana y que, sorprendentemente, no menciona en ningún momento a la pensadora judía. ${ }^{3}$ En este texto, que proviene de la plena madurez del filósofo en 1967, la categorización de las dimensiones del existir resulta más estructural, más eidética, al aplazarse la traducción política o la relevancia histórica de, sobre todo, el tercer movimiento. Por otro lado, el contraste de la descripción patočkiana del arraigo con la conceptuación arendtiana de la labor resulta, a mi juicio, especialmente fructífero; viene a dibujar una alternativa fenomenológica de singular hondura a la forma más estricta, más rígida, en que Arendt suele describir la condición del animal laborans. ${ }^{4}$

B. "El mundo natural y la fenomenología" recapitula el análisis de los movimientos de la existencia humana con la ayuda de una serie de fórmulas concentradas que resultan muy expresivas. Del primer movimiento se dice en particular que consiste en el "hacerse la vida mediante la vida misma". ${ }^{5}$ La vida de

\footnotetext{
${ }^{2}$ Por fin puede leerse una versión fiable en castellano de este gran libro, en la traducción directa del checo de Iván Ortega Rodríguez: Patočka (2016); cf. las referencias a Arendt en Patočka (2016), pp. 46-49.

${ }^{3}$ En castellano, este largo ensayo es el primer texto de la recopilación El movimiento de la existencia humana: Patočka (2004), pp. 13-56.

${ }^{4}$ La comparación entre Arendt y Patočka ha sido objeto de investigación académica en los últimos años. A modo solo orientativo cabe citar los siguientes trabajos: Bériault (2011), Faes (2012), Učnik (2010), y más recientemente Učnik (2016), y Ritter (2017). En España son de interés las alusiones que conectan ambas figuras en los trabajos de José Lasaga sobre Arendt: Lasaga (2004), o bien Lasaga (2014) así como en los estudios de Josep M. Esquirol (1995) o en el artículo de Iván Ortega (2011), o, en fin, en mi ensayo Serrano de Haro (2000). Iván Ortega es el único estudioso español conocedor además de toda la bibliografía en checo acerca del filósofo checo.
}

${ }^{5}$ Patočka (2004), p. 42. 
que aquí se trata, la vida en su revelación primera en el tiempo y en su condición fundante respecto de cualquier otra posibilidad, no es sino la existencia precaria del ser humano sobre la faz de la Tierra. El viviente se identifica con la indigencia de un cuerpo necesitado, menesteroso, que es el suyo y que despliega una movilidad constante de búsqueda y captura de los bienes que pueden satisfacer su penuria. La supervivencia del viviente depende de la apropiación de unos bienes que solo gracias a la motricidad de su propio cuerpo puede reconocer, alcanzar, consumir. Esta dinámica elemental de la experiencia discurre en el llamado por Patočka "mundo natural", o también mundo inmediato de la vida natural. La polaridad entre la Tierra y el cielo marca la geografía de este mundo primordial. La Tierra aparece al viviente como el suelo inmóvil de proximidad total, sobre el que su cuerpo se mueve y se orienta; ella es también el poder nutricio que sostiene la existencia, la fuente que provee de los bienes imprescindibles y que los renueva sin cesar. El Cielo aparece ante el viviente, en cambio, como el referente vertical de la lejanía, como el dispensador cíclico de la luz, y por ello como la instancia orientadora del tiempo, de los tiempos. La descripción del filósofo checo de estas experiencias originarias de Tierra y Cielo es memorable, pero no me detendré aquí en los diversos detalles. ${ }^{6}$ Pues bastan estos trazos fundamentales para tomar nota del claro paralelo entre el enraizamiento patočkiano en el mundo natural y la labor de nuestros cuerpos al modo arendtiano.

A primera vista diríase que "la labor de nuestros cuerpos" tal como Arendt la analiza en detalle en La condición humana es no solo la fuente directa que inspira a Patočka, sino también el modelo conceptual que él se limitaría a repetir, a glosar; a lo sumo, a enriquecer con las meditaciones fenomenológicas sobre Tierra y Cielo. La labor está determinada por la condición efímera y consuntiva de los bienes que permiten el sostenimiento de la vida, la supervivencia. El viviente humano faena o labora -cultiva, recolecta, caza, cría, protege su cuerpo de la intemperie- para comer; y a su vez se alimenta, descansa y repone así la energía del cuerpo para seguir luego faenando. El cuerpo activo se gasta y desgasta en las tareas que cubren las necesidades de este mismo cuerpo menesteroso, y una vez satisfecha la precariedad retorna el cuerpo a la fase de actividad. En este círculo inexorable, la infinitud repetitiva del proceso de necesidad-labor-consumo converge con la urgencia perentoria, a vida o muerte, de cada presente necesitado, de cada indigencia particular. Como dirá en repetidas ocasiones la filósofa, la labor "no deja nada tras de sí": nada pervive salvo la eterna recurrencia de la urgencia.

No puede extrañar, pues, que la condición humana atada a la labor se conciba por Arendt como una nuda vida, como mera existencia natural. En el estrato

\footnotetext{
${ }^{6}$ Para esta precisa cuestión puede consultarse el artículo de Maturano (1998).
} 
básico de la acción, el cuerpo humano no pasa de ser un organismo vivo que se halla inmerso por completo en el todo de la naturaleza, con la cual mantiene un intercambio constante de energías; este metabolismo denota la continuidad ontológica, si es que no la identidad, entre el individuo y su medio natural. En conclusión, el ser humano sumido en la labor está sujeto por entero al yugo de la necesidad; una determinación inexorable preside su acción incesante, y él carece no ya de la capacidad sino de la posibilidad de alterar este destino; cada día con su afán, cada instante del tiempo con su urgencia, se limitan a ratificar la condición natural de la labor. Dicho solo de otro modo, el ser humano que faena y consume es, con pleno rigor, animal laborans: "Y es verdad que está enteramente justificado el uso de la palabra "animal" en el concepto de animal laborans, frente al uso muy discutible de la misma palabra en la expresión animal rationale. Desde luego este animal laborans es solo uno del género animal que puebla la tierra, a lo sumo el más elevado".7

Ahora bien, junto al paralelismo evidente de ambos planteamientos acerca del grado básico de acción, discurre también, a mi juicio, una diferencia sumamente significativa. Y es que en la perspectiva del filósofo checo la inserción laboriosa o laborante en el mundo presupone ya un arraigo anterior. Hay un anclaje primordial que vincula al viviente no con la naturaleza provisora como un todo, sino más bien con el otro, con los otros, que ya siempre han acogido a este ser que nace en la indigencia. Del fenómeno primordial de la labor forma parte esencial el hecho de que han sido otros congéneres quienes han asistido a la infinita precariedad del nacido como humano, y quienes al proveerle de los bienes perecederos, del alimento y la protección, lo han incorporado al mundo. El movimiento primero del existir no es tanto uno que el sujeto haga al sufrir y asumir su penuria constitutiva, cuanto más bien uno en que el sujeto mismo ha sido hecho: yo he llegado a ser al recibir mi cuerpo una viabilidad primaria que él mismo es incapaz de darse. Antes de padecer la necesidad y de reaccionar a ella o, en todo caso, a la vez que esta pasividad primitiva, ha acontecido una pasividad todavía más primordial en la que fui acogido y fui por ello como llevado hasta mí, puesto en mí. Como si sólo desde el otro pues Patočka no llega a emplear las palabras aquí obvias de "madre" o "padres"-, pudiera yo hacer mío mi propio cuerpo carencial.

El matiz de concepto es tan relevante que mientras Arendt pone todo el énfasis en la indigencia extrema del mero viviente, Patočka tiene razones para hablar de una cierta plenitud originaria, de un estar lleno, sin por ello haber dejado de ser un nudo de indigencias: "El otro hace que estemos llenos, que estemos ya siempre, de algún modo, en nuestra meta, pese a todas las necesidades y carencias. El otro nos pone a cubierto de nuestras necesidades. Es el otro y, en el vínculo natural, necesario y recíproco, son los

\footnotetext{
${ }^{7}$ Arendt (1993), p. 100-101. Trad. modificada de Ramón Gil Novales.
} 
otros quienes nos ponen a cubierto y a cuya ayuda debemos que la Tierra pueda para mí llegar a ser Tierra y el cielo cielo: los otros son el hogar originario". ${ }^{8}$ Cabría sugerir que mientras Arendt hace de la labor una condición natural de la existencia humana, que remite directamente a la propia naturaleza y que presupone el metabolismo con ella y en el seno de ella, Patočka concibe este movimiento cero del existir más bien como una primera forma de intersubjetividad, que remite directamente al vínculo intersubjetivo. La encrucijada inicial no se puede describir sin más desde el proceso unitario y abarcador de la realidad natural, que no corresponde a ninguna perspectiva viviente en particular y que las abarca a todas ellas en conjunto, sino que más bien tiene lugar como el encuentro de una indigencia omnímoda que ha sido acogida infinitamente por subjetividades adultas. El orden básico de la acción es este movimiento intersubjetivo más de los otros hacia mí, hacia el nacido, que de éste, del nacido, a ningún sitio; y por ello es preciso no objetivar la incorporación al mundo natural desde fuera de las vidas concernidas, desde "el ciclo eterno de la naturaleza" que desborda de toda relación en persona, que carece de toda perspectiva en primera persona. Tal como sugería el final de la cita anterior, solo el anclaje primitivo en los otros, y por o gracias a los otros, permitiría habitar el mundo primordial, deparando el aprendizaje significativo de los ejes y categorías cardinales de lo que hay: Tierra-cielo, bienes-peligros, necesidades-satisfacciones, humanos-no humanos, naturaleza provisora, etc.

Ciertamente es una peculiar fenomenología genética la que destapa este movimiento cero de la existencia y pone de relieve su alcance crucial; éste yace en un pasado que no es recuperable por la intuición, del que no queda memoria, al que los recuerdos no llegan. Pero Patočka apunta que una afectividad raigal se trama en este acontecer primero, para operar luego en el curso posterior de la vida como una "urdimbre afectiva" -en la expresión homologable de Rof Carballo que tuvo un cierto éxito en España hace algún tiempo-; "la calidez de la vida" procedería, en efecto, de esta experiencia remota de que el vivir es posible, ya que la necesidad aunque incesante es atendida y cubierta. La familiaridad con el mundo natural, como ámbito respirable, habitable, provisor, sería el correlato de esta calidez estructural, sedimentada en el fondo del yo, en que el viviente siente su propio vivir en el mundo y que operaría como una matriz de múltiples afectos, gozos, esfuerzos, acciones. De hecho, la historia inicial de acogida personalizada no queda enterrada por los movimientos superiores de la existencia adulta; pensando ante todo en los fenómenos eróticos, Patočka señala que esta matriz puede cobrar ciertas nuevas tonalidades y direcciones en la vida posterior.

Es verdad que también La condición humana repara en la vertiente afectiva ligada a esta vida activa elemental, básica. En un fragmento del capítulo temático

\footnotetext{
${ }^{8}$ Patočka (2004), p. 41.
} 
sobre la labor hace Arendt alusión entonces a "la felicidad de estar vivo" y entiende que la estrecha continuidad entre esfuerzo corporal y gratificación, entre necesidad y satisfacción, puede experimentarse "con la misma regularidad feliz y sin propósito con que se siguen el día y la noche, la vida y la muerte". ${ }^{9}$ Pero esta bendición de la labor no parece merecer demasiado crédito de la pensadora judía, que lo tiene por un afecto superficial; lo compartimos con todas las criaturas vivientes, siempre está cercado por la penuria, siempre presto a invertirse en la desdicha de la pobreza o en el aburrimiento de la abundancia, etc. Sobre ello, el origen cultural de esta valoración se remontaría más al Antiguo Testamento, en que la vida es don de Dios, que a la filosofía griega o a la tradición política clásica. No parece, en suma, que este tratamiento arendtiano pueda parangonarse con el motivo de la calidez de la vida en el filósofo checo, que a su modo y manera sí evoca un poco a la autoafección gozosa del vivir en la fenomenología material de Michel Henry.

Con todo, la prueba última de una divergencia muy relevante que se oculta bajo la proximidad patente radica en que el modelo intersubjetivo y genético de Patočka no puede garantizar, a diferencia de la interpretación naturalista de Arendt, la realización del movimiento básico de la existencia. El cumplimiento de éste tiene algo de contingencia, no está asegurado, y con ello los movimientos superiores de la existencia: la afirmación del yo en la coexistencia social, la posibilidad de entrega o sacrificio, se asientan también sobre acontecimientos no necesarios. Pues, en efecto, cabe que el viviente humano no experimente ninguna acogida al nacer al mundo; puede ser rechazado, dejado a su suerte -que ha de ser entonces su desdicha-, puede incluso ser violentado. En estos supuestos de la criatura no querida, huérfana, abandonada, por desgracia nada imaginarios, el nacido choca dolorosamente e inerme contra sus propias necesidades. De acuerdo con el análisis de Patočka, en realidad de acuerdo con la sumarísima alusión que él hace a este asunto, el viviente tendría entonces cortado el acceso al mundo natural y a su geografía primordial. Ni naturaleza provisora, ni ámbito natural en que el humano habita y en que puede moverse con sentido, en lugar de en un mundo de la vida, el laborante humano que sufre la exclusión o el rechazo se encontraría arrojado -sugiere el ensayo- a algo así como un desierto informe; su propia vida, desprovista de la calidez raigal, será sentida, quizá a ciegas, mas con cruel evidencia, como inviable. ${ }^{10}$ Los restantes movimientos de la existencia humana descansan, a esta luz, no sobre la revelación del ser, no sobre la inserción en la naturaleza, sino sobre unos acontecimientos propicios que parten del otro, de los otros, y cuya existencia no puede darse, sin embargo, por descontada.

\footnotetext{
${ }^{9}$ Arendt (1993), p. 118.

${ }^{10}$ He comentado esta descripción de lo invivible también en mi ensayo "Fenomenología genética y humanismo", en Serrano (2017) (Puede leerse el ensayo también en: La persona. Jornada de Filosofía 2015. Tirado San Juan, V. M. (ed.), Madrid: Universidad San Dámaso, 2018.)
} 
C. Las divergencias de matiz y de énfasis entre Arendt y Patočka a propósito del movimiento de base del existir humano dejan sentir su influencia en la tematización de los órdenes superiores de la acción. Una concordancia pero discorde, o bien una discordancia relativa, que se asienta sobre una comunidad de enfoque, atraviesa la descripción del trabajo y de la praxis-entrega, y mi hipótesis es que, además de otros factores descriptivos y temáticos, ciertas diferencias significativas conectan con o remiten a la disparidad originaria entre la labor como experiencia directa de la necesidad natural y el acogimiento por los otros como incorporación al mundo. Permítaseme esbozar solo esta ampliación de la problemática.

Como es sabido, la profunda heterogeneidad del trabajo de nuestras manos respecto de la labor de nuestros cuerpos pasa, en Arendt, por el hecho de que la cosa producida está llamada a durar, está destinada a permanecer; el útil que el ser humano fabrica está concebido y creado para perdurar. La duración, la realidad y la posibilidad misma de objetos duraderos, que resisten al paso de los días y al contacto con la corporalidad, es así la enorme novedad ontológica que trae consigo el segundo orden de la acción. La pensadora judía siempre subrayó cómo la fabricación de artefactos no respondía sólo ni básicamente a motivos utilitaristas de facilitación del consumo y suavización de la penosa labor. Más bien se construyen útiles para erigir un mundo a resguardo de la naturaleza, y estos útiles, enseres, artefactos -pues, igual que en Heidegger, ningún utensilio existe en solitario o en números discretos- se integran en tramas coherentes de sentido que forman el mundo habitado por los humanos. El trazado estable, reconocible, duradero, del mundo de objetos puede entonces escapar a la abrumadora continuidad de la naturaleza, y al interponerse estas cosas fabricadas entre los seres humanos, como "la mesa entre los comensales", se instaura también el espacio compartido de la coexistencia intersubjetiva, de la interacción. Pero no me puedo detener ahora en la asombrosa potencia y flexibilidad de este modelo arendtiano. Quisiera solo apuntar la aparente paradoja de que Arendt, por haber naturalizado previamente la labor, por haberla concebido íntegramente como un metabolismo casi anónimo con el medio, ha de asumir aquí el enorme desafío de que el ser humano fabrica un mundo de objetos solo a través del cual el propio sujeto humano se constituye o crea a sí mismo: el hacedor se hace a sí mismo al hacer lo otro que él. Para Arendt no habría en rigor seres humanos antes del homo faber (solo animales laborantes), y el ser humano surgiría en y por la acción de producir las cosas que duran, el entorno que permanece; una suerte de Tathandlung, pero no reflexiva ni introspectiva sino intencional, oriunda de la creación de lo duradero. Con esta auto-génesis de la condición humana coincide también el pensamiento, tan insistente en La condición humana, de que la actividad constructora del hombre da la réplica, la respuesta, a la violencia previa del sometimiento a la labor; esta afirmación de poder, que violenta 
a la naturaleza, saca al ser humano de la tiranía previa, literalmente inhumana, de la necesidad.

Para el pensador checo, que no ha naturalizado la labor, el cuadro del segundo movimiento es algo distinto. El discípulo de Husserl presenta el orden del trabajo en una cierta heterogeneidad de sentido respecto de la vida subyacente, que no implica, sin embargo, una discontinuidad radical, absoluta. El acceso estable a los bienes nutricios, su aseguramiento por entre las contingencias naturales, la contención de la precariedad de la vida y la prolongación de las existencias humanas, todo ello depende, en efecto, de un poder que las comunidades humanas organizadas despliegan; descansa sobre las capacidades de acción que los individuos que las integran asumen y exige de éstos el ejercicio constante de una colaboración mutua. La polaridad primitiva Tierra-cielo del mundo elemental da paso ahora a una determinación objetiva de las realidades naturales y sus ciclos y a una tipificación de las formas de aprovechamiento de ellas, a su conversión en recursos disponibles; tal fijación u objetivación del entorno natural implica desde luego, como en Arendt, la disposición permanente por parte de los sujetos humanos de toda una trama de útiles e instrumentos fabricados. Y a su vez este entramado instrumental, la fabricación, posesión y disposición permanente de él, sigue remitiendo a las capacidades individuales de los sujetos para emplearlos y a las relaciones sociales de cooperación y subordinación entre ellos. Esta capacitación del sujeto humano, su incorporación a la vida adulta, no es, con todo, una prolongación de la urdimbre afectiva primordial, una prosecución por otros medios de la comunidad familiar de acogida sino que tiene lugar fuera de las cuatro paredes del hogar. El sujeto toma en sus manos su existencia presente y futura, se convierte en un centro de iniciativa y de acción y ejerce su actividad eficaz en el mundo de la coexistencia social y de la organización política. En el seno de esta intersubjetividad, que está atravesada por jerarquías y relaciones de poder, el viviente humano que experimentó la calidez de la vida vincula ahora su identidad, al menos en parte esencial, a la función que desempeña en la sociedad y al lugar que en ella le corresponde; uno mismo llega a constituirse, pues, como individuo humano activo sólo en un marco de relaciones sociales, que implican cooperación, no menos que subordinación, supeditaciones, jerarquías.

Para Patočka, pues, lo que faltaba antes del segundo movimiento de la existencia no es la diferencia específica humana sin más, la peculiaridad distintiva de lo humano; mirado desde la primera persona del nacido y acogido, lo que no comparecía es la subjetividad con poder de acción, el sujeto finito. La sensibilidad más bien infinita de la infancia inaugural, en la asimetría completa con los otros provisores, dará paso, con el tiempo, a un yo que es a la vez poderoso y limitado, que actúa con y contra otros más o menos iguales a él. Y esta transición de la afección 
infinita del viviente a la iniciativa finita del humano no se produce directamente por la presencia interpuesta de los útiles, sino por la participación del individuo en una intersubjetividad de yoes adultos; éstos comparten el mundo de las cosas y su trasfondo natural mientras siguen acogiendo a los nuevos vivientes que nacen al mundo. Aquí no hay, pues, como en Arendt, una génesis espontánea de la condición humana en general por la fabricación de lo que dura, cuanto más bien una autoconstitución de cada yo humano adulto que en el movimiento de encuentro y desencuentro con los otros llega a ser quien es.

Apenas puedo ya detenerme en la consideración de si las tematizaciones respectivas y diversas del tercer movimiento de la acción acusan huellas significativas de la comprensión dispar del movimiento inicial. Es imposible, con todo, no recordar de inmediato que Arendt defendió incansablemente cómo la natalidad y, con ella, la pluralidad son los verdaderos principios ontológicos que están a la base de la praxis política, en la raíz de la novedad de las acciones humanas. La convivencia en libertad, la coexistencia en la polis, debe siempre renovarse, pero puede de hecho hacerlo en razón de que cada ser humano es una singularidad imprevisible, una individuación no intercambiable. Justamente por ello el ciudadano singular puede dar inicio a procesos inesperados de acción para la convivencia, o bien puede interrumpir procesos inertes que pesaban sobre la coexistencia; puede así singularizarse cara a los otros. Con o sin la cita de Agustín de Hipona que Arendt hizo famosa (Initium ut esset homo creatus est), ¿cómo no preguntarse, en la perspectiva de este ensayo, si esta natalidad principio ontológico de la praxis tiene algo, mucho o nada que ver con la natalidad como situación primaria en que los seres humanos aparecen en el mundo bajo el yugo implacable de la necesidad natural? La propia Arendt habló, sin duda, de un "segundo nacimiento" en que lo hecho y lo dicho en público confiere a los humanos un segundo nombre, pero ¿resulta entonces "natalidad" una categoría puramente equívoca, una metáfora que expresa por igual la constricción natural y el origen de la libertad? En definitiva, si se nace a la labor, que es no-mundana y no-política, ¿no es el surgimiento de la individualidad por y en la acción política un contra-nacimiento?

Ciertamente que el tercer movimiento de la existencia tal como Patočka lo esboza de manera siempre tentativa y enigmática no parece el mejor recurso para afrontar las perplejidades y paradojas de la praxis que Arendt tematiza. Poco importa a este respecto la coincidencia muy notoria de que ambos pensadores admiten sólo un tercer y último derrotero de la existencia, más allá de la acogidalabor y del empoderamiento-trabajo; no innumerables movimientos más, no varios más, ni siquiera una cuarta posibilidad. Esta tercera navegación es, además, un acontecimiento inusual, nada común, que irrumpe en contadas ocasiones, a contados sujetos, que no se deja institucionalizar. La entrega de uno mismo, el sacrificio por 
el otro sin cálculo de retorno, sin previsiones de utilidad, procede en la dirección contraria a la afirmación social del sujeto en el segundo movimiento, pero no se dejaría entender de no ser por la insatisfacción oscura, creciente, que el sujeto experimenta con la funcionalización de su existencia al servicio de la organización social. Un poso incesante de decepción o vacío motiva a trascender la centración sobre uno mismo y sobre el presente atomizado de las tareas sociales siempre repetidas, que solo ofrecen un futuro homogéneo, un aplazamiento mortecino del fin. Pero esta inquietud incierta que cuestiona y perturba al individuo, que puede llegar a conmover el suelo de seguridades de su existencia, no es tampoco una irrupción en la edad tardía de la experiencia infantil de plenitud; no se trata de una búsqueda desesperada de la calidez perdida de la vida, como si el tercer derrotero brotara del requerimiento inconsciente de un principio de placer que desafía al principio de realidad. El movimiento del combatiente que acepta el sacrificio de su vida por otros -ejemplos de Ensayos heréticos de filosofía de la historia-, el del resistente o disidente pacífico que hace frente a un poder brutal-ejemplo de los textos finales en torno a "Carta 77" -, el del sujeto finito que hace suya la pregunta radical por el todo de lo que aparece -ejemplo de "El mundo natural y la fenomenología" -, hacen una experiencia nueva de la propia existencia que, de alguna manera, interpela a los otros y apunta a una promesa de encuentro intersubjetivo más auténtico. ¿Es esta situación más propiamente un segundo nacimiento, un nuevo comienzo del existir? Ante la posibilidad asumida de la propia muerte, ante su proximidad no aplazada, no encubierta, ¿no se produce el descubrimiento desconcertante de que "ser [para el humano] significa ser en una absoluta unicidad expuesto a una amenaza total"?"1 ¿Y no sugiere Patočka que esta revelación encierra un señalado valor político, ya que, no siendo una verdad objetiva, sí convierte al individuo conmovido en testigo de una verdad inobjetiva que permite criticar la coexistencia establecida, inerte, mortecina, y albergar la promesa teleológica de renovación de la intersubjetividad? Pero, como dije, no contamos con claridades suficientes para sondear si ambas fenomenologías de la acción, tan emparentadas, tan irreductibles, terminan por aproximarse aún más y casi converger al encomendar el cuidado político del mundo a una dimensión libre de la existencia que en sí misma es problemática, incierta, incluso desconcertante. Mi impresión es que incluso para valorar este horizonte último de ambas filosofías es esencial reconstruir fenomenológicamente, con máximo rigor, el movimiento inicial de la existencia.

\footnotetext{
${ }^{11}$ Patočka (2004), p. 49.
} 


\section{BIBLIOGRAFÍA}

Arendt, Hannah (1993). La condición humana. Barcelona-Buenos Aires-México: Paidós.

Bériault, Xavier (2011). "Hannah Arendt et Jan Patočka: la Relation entre la Philosophie et le Monde". Actas Universitatis Carolinae. Studia Philosophica Europeanea 1/1, pp. 137-151.

Esquirol, Josep M. (1995). Tres ensayos de filosofía política. Barcelona: PPU.

Faes, Hubert (2012). "Naturalité, Artificialité, Historicité du monde commun. Hannah Arendt et Jan Patočka". En Jan Patočka. Liberté, existence et monde commun, Frogneux, Nathalie (ed.). Bruselas: Le Cercle Herméneutique Éditeur, pp. 31-42.

Lasaga, José (2004). "El modelo antropológico de Hannah Arendt: la condición del animal humano". En Modelos antropológicos del s. XX: M. Scheler, D. von Hildebrand, E. Stein, M. Merleau-Ponty, J.-P. Sartre y H. Arendt. Sellés, Juan Fernando (ed.). Cuadernos de Anuario Filosófico. Serie Universitaria, nº 166, pp. 115-141.

Lasaga, José (2014). "Vigencia de Arendt". Revista de Occidente 400, pp. 44-63.

Maturano, Ángel Garrido (1998). "El cielo en las filosofías de Husserl, Patočka y Heidegger" (1 ${ }^{\circ}$ parte)". Revista de Filosofía Universidad de Costa Rica XXXVI/90, pp. 613-621.

Ortega Rodríguez, Iván (2011). "Política, subjetividad libre y mundo: apuntes para una investigación fenomenológica. Investigaciones fenomenológicas, Serie Monográfica 3, 321-330.

Patočka, Jan (2004). “El mundo natural y la fenomenología”. En: Patočka, Jan. El movimiento de la existencia humana. Padilla, Teresa, Ayuso, Jesús María, Serrano de Haro, Agustín (trads.). Madrid: Encuentro, pp. 13-56.

Patočka, Jan (2016). Ensayos heréticos sobre filosofía de la historia. Ortega Rodríguez, Iván (trad.). Madrid: Encuentro.

Ritter, Martin (2017). "Patočka's Care of the Soul Reconsidered: Performing the Soul Through Movement”. Human Studies 40/2, pp. 233-247.

Serrano de Haro, Agustín (2000). "Tres perspectivas sobre la fenomenología en su siglo". Diálogo filosófico 46, pp. 4-34.

Serrano de Haro, Agustín (2017). "Fenomenología genética y humanismo". En La pregunta por el humanismo hoy. Tres perspectivas. Pulido, Jorge E. (ed.). Bogotá: Editorial Bonaventuriana Universidad de San Buenaventura de Bogotá, pp. 21-36 (íd. (2018). En La persona. Jornada de Filosofía 2015. Tirado San Juan, Víctor Manuel (ed.). Madrid: Universidad San Dámaso).

Učnik, Lubica (2011). "Human Existence: Patočka's Appropriation of Arendt”. En Phenomenology 2010. Volume 1, Selected Essays from Asia and Pacific. Yu, Chung-Chi (ed.), pp. 409-434. Bucarest: Zeta Books.

Učnik, Lubica (2016). The Crisis of Meaning and the Life-World: Husserl, Heidegger, Arendt, Patočka. Ohio University Press. 